\title{
The Integration of Augmented Reality into MOOC's in Vocational Education to Support Education 3.0
}

\author{
https://doi.org/10.3991/ijim.v16i03.28961
}

\author{
Ahmad Mursyidun Nidhom ${ }^{1(\bowtie)}$, Andika Bagus Nur Rahma Putra ${ }^{1}$, \\ Azhar Ahmad Smaragdina ${ }^{1}$, Gres Dyah K N ${ }^{1}$, Muhammad Afnan Habibi ${ }^{1}$, \\ Jailani Md Yunos ${ }^{2}$ \\ ${ }^{1}$ Universitas Negeri Malang, Malang, Indonesia \\ ${ }^{2}$ Universiti Tun Hussein Onn Malaysia, Johor, Malaysia \\ nidhom.ft@um.ac.id
}

\begin{abstract}
This research discoverable (1) the development of a MOOC (Massive Open Course Online) learning innovation that incorporates Augmented Reality; (2). The use of the concept of AI Injected e-Learning (The Future of Online Education) in Vocational High Schools, which supports the idea of Education 3.0. This study employs a quantitative method to educational research and development, with research sample vocational students. The findings of this research lead to the following conclusions: (1) The efficacy and efficiency of MOOC's learning innovation integrated Augmented Reality was evaluated to be 87.3 percent in a usability test; (2). The application of the concept of Education 3.0 proved to have a significant impact on learning comfort, as evidenced by a questionnaire instrument that revealed that around $85.4 \%$ of users believed that online and face-to-face learning provided flexibility in learning, $12.2 \%$ felt that learning was normal, and $10 \%$ felt that learning was not required; (3). The results of the correct hypothesis are acquired from the quantitative data with a significance value of greater than 0.5 , indicating that MOCC's integrated learning utilizing Augmented Reality has resulted in a significant increase in the learning outcomes of vocational high school students by 38 percent.
\end{abstract}

Keywords-MOOC's, education 3.0

\section{Background}

Because there are always new things to learn, the creation of learning innovations is currently considered to have a broad scope. In these circumstances, interactive learning can help build a good, friendly, and comprehensive learning environment [1],[2]. Learning innovation is a benchmark in the Development of comprehensive learning that can increase learning motivation through the development of an online learning system that is integrated with MOOC. It is not new that we know MOOC as an online learning system that is integrated with the Augmented Reality system [3],[4], but what needs to be explored further is the 3.0 education concept embedded in it providing a blend of learning innovations that can accumulate in terms of student-based learning. and monitored directly by the teacher. MOOC is a concept that is predicted to be a good 
concept in learning, this is because MOOC can be accessed from all over the world and can be directly (free) used by students around the world so that access to information and learning can be spread easily [5].

Education is the Development of a human being to be able to actualize and increase his role in life in social life. It is this role that inspires improvements, strategies or learning approaches. Education also has several improvements to be able to bridge the gap with the Development of technology that is increasingly rapidly nowadays. Students have started to leave conventional media into interactive multimedia in various forms (mobile, augmented reality to artificial intelligence) [6],[7]. As a result, education must adapt as well. One of the modifications presented is the existence of a version for education, with the expectation that each new version would include new features that will make learning easier for students [8]. The update or upgrade in question is the installation of Education 1.0, 2.0, and 3.0, which was inspired by the growth in static web versions 1.0, 2.0, and 3.0, each of which has major improvements in terms of website facilities and usability.

The primary principle of Education 3.0 is that education can be altered, customized, and flexibly conditioned to meet the needs of pupils. Educators facilitate basic learning concepts, and all learning activities are centered on educators, in contrast to Education 1.0 and Education 2.0. The essential principle of open learning is carried over into Education 3.0, which is organized in a pattern (Connectors, Creators, Constructivists). These three patterns have a long-term association with learning, particularly in terms of boosting motivation and interest. This concept is the forerunner of National Development in the field of learning innovation throughout the country, by emphasizing the actual growth process in the quality of education and following the trend of technological developments, of course providing accelerated distribution of learning that comes from reliable learning sources. The concept of equal distribution of learning needs to be balanced with the existence of learning content that can be accessed widely and easily, one of which is the distribution of learning through information technology in current learning [9]. MOOC's is a learning resource that is currently needed in online and offline learning, the idea of combining the two (MOOC's and Augmented Reality) comes from the results of research which states that in 2020 there were almost $85.32 \%$ of active smartphone users who can access the internet through data. private or free wifi hotspot. This of course proves that digital era learning, in this case online learning, has no problems in its application [10],[5]. In 2020 the Indonesian government also launched a Free Internet Quota for students and teachers, of course this is a breath of fresh air and assistance that can distribute learning evenly through the MOOC's integrated Augmented Reality scheme, besides that youth and accessibility of learning materials are embedded with object 3 Dimensions makes learning easier and interactive for the learning process (Figure 1). 


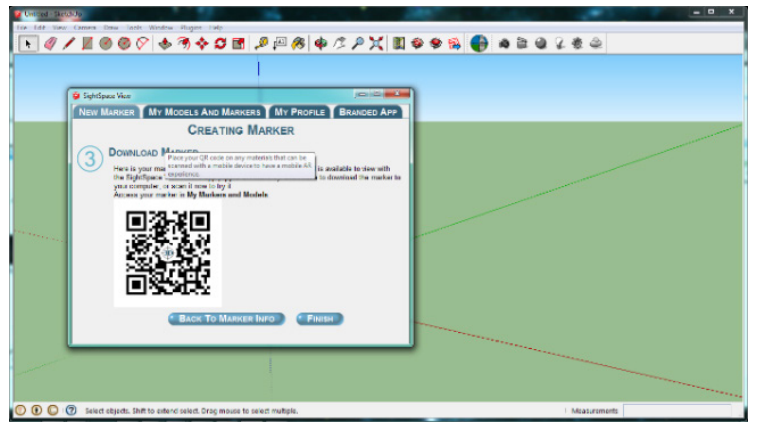

Fig. 1. MOOC's design integrates augmented reality

MOOC's Development, which is given Augmented Reality accessibility, not only carries the concept of flexibility in its application [11], this Development is also based on learning innovations that prioritize teacher creativity to provide complete learning content, through 3-dimensional objects that can be directly accessed by students and of course standardized material through material expert validation and media expert validation. Preliminary research also concluded that MOOC's users who were sampled through programming courses (Preliminary Test and Final Test) provided a statement through a questionnaire that the role of MOOC's integrated with Augmented Reality gave a percentage of about $84 \%$ as the main supplement of learning, by using this combination students' understanding increased. inline with what is captured by students through the learning process [10],[12], with a mechanism like this students will be student centered and creative [13],[14].

According to [15],[16], also mentions that the use of MOOC's which is integrated with Augmented Reality in the learning process must have 3 criteria so that it can be used in learning, namely user friendly, user usability and effectiveness of use. User Friendly refers to the use of MOOC's integrated Augmented Reality that is easy to use through applications that do not make it difficult for users, so that users will get convenience and do not feel difficult, this usability is emphasized on the level of system quality that is easy to learn and remember and encourages users to use the application as learning. Usability of use is related to the concept of the extent to which the application can be used as a relevant learning resource and can be used as a reference in learning, through a series of tests to see the reliability of MOOC's integrated with Augmented Reality.

While the effectiveness of use is testing to test MOOC's later when used can be applied by hardware with low or hard specifications, this is important to do so that the effectiveness of MOOC's can be used by smartphones and devices that may be low end by students and can be generalized in online learning that is integrated. The goal is that MOOC's AR integrated can be accessed by anyone in any part of the world and with any device as long as it is connected to the internet network. 


\section{Methods}

The development method in developing the MOOC's integrated Augmented Reality product uses Research and Development or commonly referred to as R\&D where this method is carried out by referring to conclusions and procedural steps that are integrated with 10 concrete steps for efficient, flexible and effective product development, as follows: these steps are presented in (Figure 2).

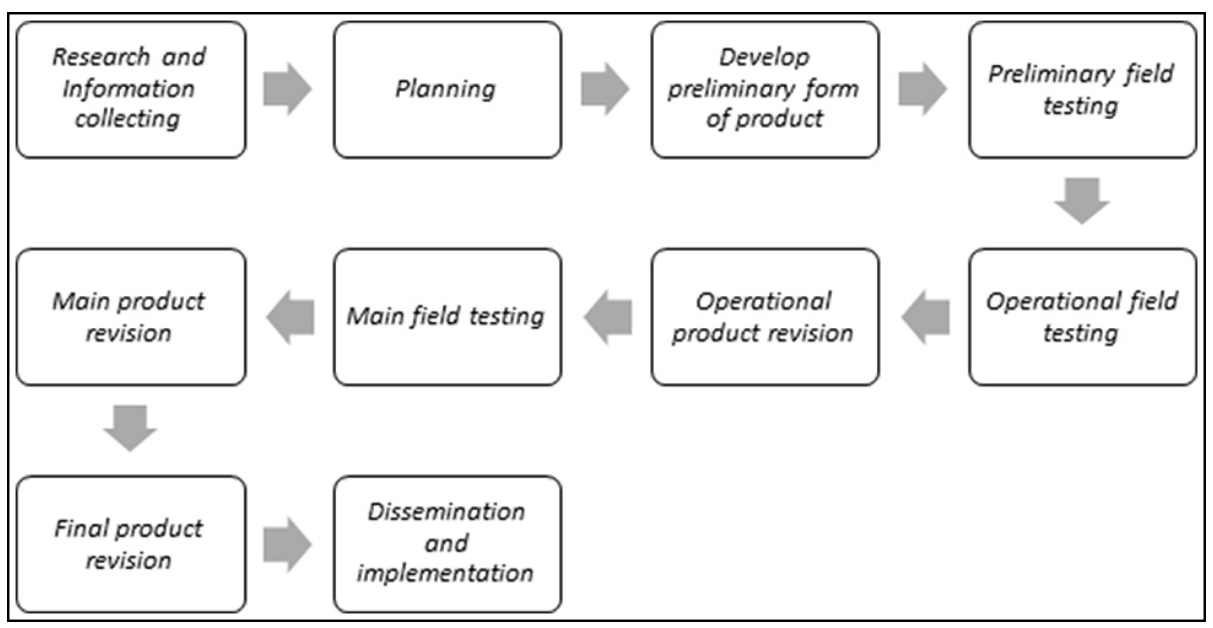

Fig. 2. Design stages of R \& D borg and gall

The 10 procedural steps in $\mathrm{R} \& \mathrm{D}$ are a mechanism for obtaining highly efficient products, through the concept developed borg \& gall concrete steps were obtained, including: (1) Information gathering stage for research through preliminary studies and field observations to knowing the extent to which the product can solve the problem; (2) The product planning stage which refers to problem-based design, the problem to be solved is then made a rough design to be continued in the next stage; (3) The pre-product planning stage begins with prototyping the results of product planning; (4) The preliminary test phase in the field is carried out with small and large group trials through prototyping that has been developed; (5) Revision stage of the developed product, in this case MOOC's integrated AR after being tested in small and large groups to get revision results that need to be improved for product perfection; (6) The field testing phase is based on the results of the Development to see the toughness of the product; (7) Operational product revisions that may be obtained in field tests; (9) The final revision stage which is final testing and has been refined in several previous stages and the product is ready to be distributed and used in general; (10). The full socialization and implementation stages in the learning process, in this case MOOC's integrated Augmented Reality can already be used in the learning process and is ready to be used as a supplement that goes through various stages in its development. 


\section{$3 \quad$ Results and discussion}

The results and discussion of the Development of MOOC's integrated Augmented Reality will discuss the Development of learning content in MOOC's, the learning content consists of animation and video which is integrated using 3 Dimensional objects that can be displayed by Augmented Reality. This MOOC's product represents the Development of learning innovations with the concept of flexibility and accessibility of application usage. The results of the Development of MOOC's products include learning content as the main source of students in the teaching and learning process, then learning content which contains learning modules (E-Modules), videos and job sheets which are used in the Computer Graphics course with Basic Competencies of Introduction to 3 Dimensional Objects. Although it was developed in the Graphics course, the generalization of this product can also be used in other courses. MOOC's which were developed are likened to a supermarket that provides all kinds of kitchen needs that students can choose from, students can choose according to their learning needs with a meaning such as supermarkets, students can choose their own learning needs so that it can greatly increase students' learning motivation.

MOOC's is also combined with education 3.0 where this concept was developed based on the selection of materials that are in sync with the needs of the industry so that later students are able to compete in the industrial world. This mechanism is indeed embedded in MOOC's, especially in the selection of materials that can be selected according to students' abilities, both with asynchronous and synchronous learning methods. The following is a product development process.

\subsection{Sub instrument development}

In the first test, it resulted in the Development of MOOC's integrated Augmented Reality by developing an E-Module that will be used in MOOC's learner content, [17] this module was developed based on the needs of the Computer Graphics course, consisting of 9 Main Modules whose Development is based on basic competencies and already validated by a material expert who has been teaching the material for more than 10 years, the selection of the sub-instrument Development is related to the basic competencies that must be achieved by students to be able to pass graduation in the course. The following is a description of the module that was developed into a sub-instrument development which can be seen in Table 1 . 
Table 1. Details of sub instrument development

\begin{tabular}{|l|l|l|}
\hline \multicolumn{1}{|c|}{ No } & \multicolumn{1}{c|}{ Modul Name } & \multicolumn{1}{c|}{ Sub Discussion } \\
\hline 1 & First Module & Application of the Open GL Concept \\
\hline 2 & Second Module & 2 Dimensional Primitive Object \\
\hline 3 & Third Module & 2 and 3 Dimensional Object Transformation and animation \\
\hline 4 & Fourth Module & Keyboard Interaction and Special Keyboard \\
\hline 5 & Fifth Module & Mouse Interaction and Double Click \\
\hline 6 & Sixth Module & 3-dimensional objects \\
\hline 7 & Seventh Module & lighting \\
\hline 8 & Eighth Module & Mapping \\
\hline 9 & Ninth Module & Texturing \\
\hline
\end{tabular}

The Augmented Reality development embedded in MOOC's also uses Four D Development Research whose development mechanism is actually very similar to R\&D but is more concise than and faster, the reason for this Four D is so that Augmented Reality developed can be demonstrated and aims to produce new products. through the Development process [18],[19]. Four D uses 4 simple special stages, namely (1) Define the product, which in this case is augmented reality that is ready to be used through a series of tests, then (2) Discover which contains the design of the project being developed, including the framework and wireframes of AR programming; (3) Develop is the process of developing AR products based on the layout of the project framework; and finally the final stage (4). It is a demonstration and dissemination through the Google Playstore and Appstore to see how users respond to the learning concepts that have been developed [12],[20] The 4 steps of Four D in detail can be seen in Figure 3.

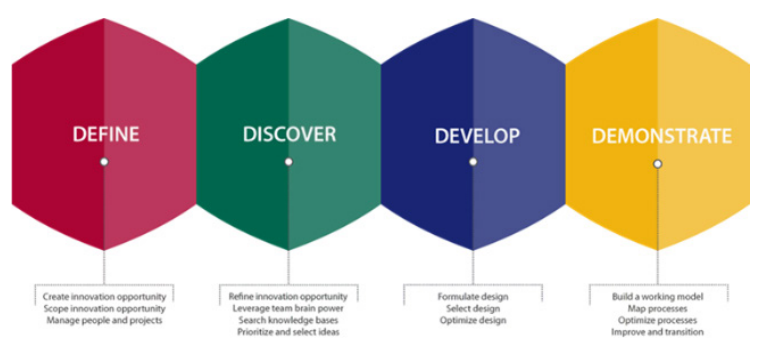

Fig. 3. Four D instrument design

\subsection{Testing of augmented reality markers}

AR marker testing was conducted to find out how strong the readability level of the marker was towards the reader, this was important so that the concept of flexibility and ease factors was found in the application, following Figure 4 is MOOC's integrated Augmented Reality marker. 


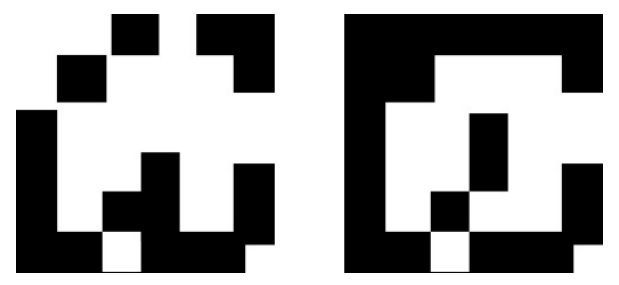

Fig. 4. MOOC's AR marker

The process carried out is to make a sampling of the markers that have been made, with sampling carried out thoroughly, it is expected to get a marker that has a level of strong readability, a strong level of accuracy and a high level of information delivery. The use of these markers is based on experimental distance, from the lowest to the highest level, here are Figure 5 Levels of readability Marker in MOOC's research integrated Augmented Reality.

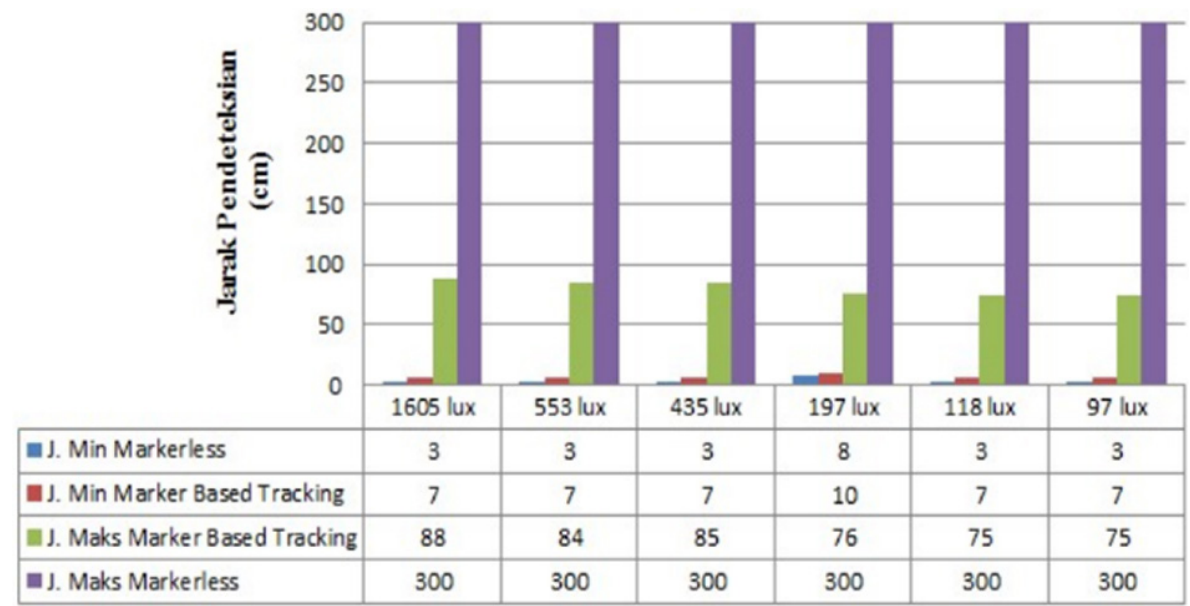

Fig. 5. Level of marker readability

In Table 2 after the readability level test is done, distance test is done, this is done to anticipate the user using more than the specified distance, which is $50 \mathrm{~cm}$, after the marker distance test is done, it turns out the results exceed the standard, namely the marker is able to read distance of $80 \mathrm{~cm}$ [21], this proves that the readability test is valid so that it can help the level of distance in the marker distance test [22].

Table 2. Level of marker readability

\begin{tabular}{ccccccccccccc}
\hline & \multicolumn{1}{c}{ Pengujian Jarak (cm) } & \multicolumn{4}{c}{ Ket. Jarak } \\
\cline { 2 - 12 } Metode Tracking & $\mathbf{3}$ & $\mathbf{5}$ & $\mathbf{1 0}$ & $\mathbf{2 0}$ & $\mathbf{3 0}$ & $\mathbf{4 0}$ & $\mathbf{5 0}$ & $\mathbf{8 0}$ & $\mathbf{3 0 0}$ & J. Min & J. Max \\
\hline $\begin{array}{c}\text { Marker Based } \\
\text { Tracking }\end{array}$ & $\mathrm{T}$ & $\mathrm{T}$ & $\mathrm{Y}$ & $\mathrm{Y}$ & $\mathrm{Y}$ & $\mathrm{Y}$ & $\mathrm{Y}$ & $\mathrm{Y}$ & $\mathrm{T}$ & $\mathbf{7} \mathrm{cm}$ & $84 \mathrm{~cm}$ \\
Markerless & $\mathrm{Y}$ & $\mathrm{Y}$ & $\mathrm{Y}$ & $\mathrm{Y}$ & $\mathrm{Y}$ & $\mathrm{Y}$ & $\mathrm{Y}$ & $\mathrm{Y}$ & $\mathrm{Y}$ & $3 \mathrm{~cm}$ & $300 \mathrm{~cm}$ \\
\hline
\end{tabular}




\subsection{Testing the effect on Education 3.0 in vocational high schools}

Testing the effect on Education 3.0 applied to Secondary School students in vocational education resulted in 87.3 levels of effectiveness, efficiency and usability tests carried out on 120 respondents or 3 classes with random sampling, along with the description in Table 3.

Table 3. Distribution of test variable results

\begin{tabular}{|c|c|c|c|c|c|}
\hline \multicolumn{6}{|c|}{ t-test for Equality of Means } \\
\hline t & df & Sig. (2-tailed) & Mean Difference & & $r$ Difference \\
\hline 1.130 & 68 & .678 & 2.638 & & 186 \\
\hline \multicolumn{2}{|c|}{ No. } & Sub Variable & \multicolumn{2}{|c|}{ Total Variable } & Percentage \\
\hline 1. & & Effectivity & \multicolumn{2}{|l|}{5 variable } & $23 \%$ \\
\hline 2. & \multicolumn{2}{|r|}{ Efficiency } & \multicolumn{2}{|l|}{5 variable } & $30 \%$ \\
\hline \multirow[t]{2}{*}{3.} & \multicolumn{2}{|r|}{ Usability Test } & \multicolumn{2}{|l|}{7 variable } & $34,3 \%$ \\
\hline & \multicolumn{2}{|c|}{ Total } & 17 variable & & $87,3 \%$ \\
\hline
\end{tabular}

From the results of the test variables, it can be seen in Table 3 that the significance is at 0.678 , this is greater than the significance of 0.5 with STD Deviation 2.186 and $\mathrm{df} 68$, this shows very good results, so it can be concluded that MOOC's can increase student motivation in learning, through Testing the effectiveness, efficiency and usability test also got good results, the range value on all aspects is $87.3 \%$ which is in the high category with 17 variables studied, indicating that this Development is feasible and ready to be used as a whole. In-depth exposure to these 17 variables has an impact when applied to MOOC's integrated Augmented Reality; this proves that the concepts obtained in preliminary research from observations, field studies, and literacy studies are appropriate and can be scientifically justified. The results of this test are also included in the main conclusions in this study.

In the Variable learning comfort also obtained results that fall into the good category with $85.4 \%$ results which indicate that the learning comfort obtained can be used as a benchmark in product application. The following in Table 4 is shown in full.

Table 4. Variable learning comfort

\begin{tabular}{|l|l|c|}
\hline \multicolumn{1}{|c|}{ No } & \multicolumn{1}{|c|}{ Conb Indicator } & Percentage (\%) \\
\hline \multicolumn{1}{|c|}{ Content Description } & 79 \\
\hline 1. & Relevance of learning content and objectives to be achieved & 82 \\
\hline 2. & Relevance of objectives and basic competencies used & 81 \\
\hline 3. & Media compatibility and basic competencies based on learning objectives & 77.5 \\
\hline 4. & The whole content is appropriate & 79 \\
\hline 5. & Clarity in learning content & 77.5 \\
\hline 6. & Level of understanding of the content & 85 \\
\hline 7. & Conformity between the content of the material and the images displayed & \multicolumn{1}{|c|}{} \\
\hline
\end{tabular}


Table 4. Variable learning comfort (Continued)

\begin{tabular}{|l|l|c|}
\hline \multicolumn{2}{|c|}{ Sub Indicator } & Evaluation Description \\
\hline \multicolumn{2}{|c|}{ No } & \multicolumn{2}{|c|}{} \\
\hline 8. & Consistency of evaluation and learning objectives to be achieved \\
\hline 9. & Clarity of the structure of the material content & 77.5 \\
\hline 10. & Feedback according to learning content & 77.5 \\
\hline 11. & The effectiveness of the learning strategies applied in the learning process & 78 \\
\hline 12. & Product suitability for student learning styles & 72,5 \\
\hline 13. & The effect of the project on increasing motivation & 80 \\
\hline 14. & MOOC's products can be used as self-study & 83.3 \\
\hline \multicolumn{2}{|}{ TOTAL } & 80 \\
\hline
\end{tabular}

\section{Conclusion}

This integrated Augmented Reality MOOC researcher reveals several issues, including: (1). Development of MOOC's (Massive Open Course Online) learning innovation integrated Augmented Reality that is intended for vocational high school students; (2). The application of the concept of AI Injected e-Learning (The Future of Online Education) which supports the concept of Education 3.0 in Vocational High Schools with a variety of sub-variables that indicate an increase in student learning outcomes; and (3). The results of MOOC's Development are integrated with Augmented Reality that can improve learning styles and increase learning outcomes of vocational high school students. This study uses a model of Development of educational research and Development with a quantitative approach, research sampling was carried out in vocational high schools in Malang and Batu City. The results of this study take the following conclusions: (1) The development of MOOC's (Massive Open Course Online) learning innovation integrated Augmented Reality has a value of effectiveness and efficiency in usability test estimated to be $87.3 \%$ which indicates a high level of user comfort in the user friendly category and efficient use of the application; (2). The application of the concept of Education 3.0 proved to have a significant impact on learning comfort, through a questionnaire instrument that proved that around $85.4 \%$ of the users considered that online and face-to-face learning provided flexibility in learning, $12.2 \%$ of respondents felt normal with learning, while $10 \%$ feel not needed; (3). From the quantitative data the results of the correct hypothesis are obtained with a significance value of more than 0.5 , thus proving that there is a significant increase in the learning outcomes of vocational high school students by $38 \%$ after MOCC's integrated learning using Augmented Reality.

\section{$5 \quad$ Acknowledgment}

This development research is supported by the Universitas Negeri Malang through licensing of data collection and full support for the use of the laboratory of the Electrical Engineering Department, the Engineering Faculty, Universitas Negeri Malang. 
Thank you very much to those who have assisted in this development research, especially to vocational students at the Universitas Negeri Malang.

\section{References}

[1] A. M. Nidhom, A. S. KH, and D. A. Sudjimat, "Hubungan Kesiapan Belajar, Lama Pembelajaran, Kesesuaian Tempat dan Partisipasi DU/DI dengan Hasil Prakerin Peserta Didik Kompetensi Keahlian TKJ di SMK Kota Batu," Innov. Vocat. Technol. Educ., vol. 11, no. 1, pp. 1-14, 2015, doi: https://doi.org/10.17509/invotec.v11i1.4832

[2] N. M. Alzahrani and S. Lajmi, "AugmentedBook: A Collaborative E-Learning Augmented Reality Platform BT - Human Interaction and Emerging Technologies,” 2020, pp. 282-288, doi: https://doi.org/10.1007/978-3-030-25629-6 44

[3] A. Physics and M. Sciences, "A Model for an Augmented Reality Tool in Tumour Removal Laparoscopic Surgery," 2020.

[4] N. Elmqaddem, "Augmented Reality and Virtual Reality in education. Myth or reality?," Int. J. Emerg. Technol. Learn., vol. 14, no. 3, pp. 234-242, 2019, doi: https://doi.org/10.3991/ ijet.v14i03.9289

[5] J. Castaño-Muñoz and M. Rodrigues, "Open to MOOCs? Evidence of Their Impact on Labour Market Outcomes,” Comput. Educ., vol. 173, p. 104289, Nov. 2021, doi: https://doi. org/10.1016/j.compedu.2021.104289

[6] A. Bahari, X. Zhang, and Y. Ardasheva, "Establishing a computer-assisted interactive reading model," Comput. Educ., vol. 172, Oct. 2021, doi: https://doi.org/10.1016/j. compedu.2021.104261

[7] R. García-Pérez, J.-M. Santos-Delgado, and O. Buzón-García, "Virtual Empathy as Digital Competence in Education 3.0," Int. J. Educ. Technol. High. Educ., vol. 13, no. 1, p. 30, Jul. 2016, doi: https://doi.org/10.1186/s41239-016-0029-7

[8] Q. Wang, Muhammad Saqib Khan, and Muhammad Kamran Khan, "Research in Business \& Social Science Predicting User Perceived Satisfaction and Reuse Intentions Toward Massive Open Online Courses ( MOOCs ) in the Covid-19 Pandemic: an Application of the Utaut Model and Quality Factors," Res. Bus. Soc. Sci., vol. 10, no. 2, pp. 1-11, 2021, doi: https://doi.org/10.20525/ijrbs.v10i2.1045

[9] A. L. L. Sing, A. A. A. Ibrahim, N. G. Weng, M. Hamzah, and W. C. Yung, "Design and Development of Multimedia and Multi-Marker Detection Techniques in Interactive Augmented Reality Colouring Book BT - Computational Science and Technology,” 2020, pp. 605-616, doi: https://doi.org/10.1007/978-981-15-0058-9 58

[10] A. Margaryan, M. Bianco, and A. Littlejohn, "Instructional quality of Massive Open Online Courses (MOOCs)," Comput. Educ., vol. 80, pp. 77-83, 2015, doi: https://doi.org/10.1016/j. compedu.2014.08.005

[11] R. O. Kellems, C. Charlton, K. S. Kversøy, and M. Györi, "Exploring the Use of Virtual Characters (Avatars), Live Animation, and Augmented Reality to Teach Social Skills to Individuals with Autism," Multimodal Technol. Interact., vol. 4, no. 3, pp. 1-11, 2020, doi: https://doi.org/10.3390/mti4030048

[12] L. Han, T. Zheng, Y. Zhu, L. Xu, and L. Fang, "Live Semantic 3D Perception for Immersive Augmented Reality,” IEEE Trans. Vis. Comput. Graph., vol. 26, no. 5, pp. 2012-2022, 2020, doi: https://doi.org/10.1109/TVCG.2020.2973477

[13] A. M. Velentza, N. Fachantidis, and I. Lefkos, "Learn with Surprize from a Robot Professor," Comput. Educ., vol. 173, Nov. 2021, doi: https://doi.org/10.1016/j.compedu.2021.104272 
[14] S. Eltalhi, H. Kutrani, R. Imsallim, and M. Elrfadi, "The Usability of BenKids Mobile Learning App in Vocabulary Teaching for Preschool," pp. 4-18, doi: https://doi.org/10.3991/ ijim.v15i24.22237

[15] B. Bajči et al., "Work-in-Progress: Development of Augmented Reality Application for Learning Pneumatic Control BT - Cyber-physical Systems and Digital Twins," 2020, pp. 711-718, doi: https://doi.org/10.1007/978-3-030-23162-0 64

[16] N. Schiffeler, V. Stehling, M. Haberstroh, and I. Isenhardt, "Collaborative Augmented Reality in Engineering Education BT - Cyber-physical Systems and Digital Twins," 2020, pp. 719-732, doi: https://doi.org/10.1007/978-3-030-23162-0_65

[17] A. M. Nidhom et al., "The Effect of Integrated Project based Learning MOOCs on Student Result of Vocational High School Students," no. January, pp. 123-127, 2020, doi: https:// doi.org/10.5220/0008783401230127

[18] P. A. Rauschnabel, "Augmented Reality is Eating the Real-World! The Substitution of Physical Products by Holograms," Int. J. Inf. Manage., vol. 57, no. October 2020, p. 102279, 2021, doi: https://doi.org/10.1016/j.ijinfomgt.2020.102279

[19] B. Marques et al., "Informing the Use of Visual Assets in Industrial Augmented Reality BT - Design Tools and Methods in Industrial Engineering," in Education + Training, Jan. 2020, vol. 61, no. 9, pp. 755-767, doi: https://doi.org/10.1007/978-3-030-15160-7 135

[20] L. Daling, A. Abdelrazeq, C. Sauerborn, and F. Hees, "A Comparative Study of Augmented Reality Assistant Tools in Assembly BT - Advances in Usability and User Experience," 2020, pp. 755-767, doi: https://doi.org/10.1007/978-3-030-19135-1 74

[21] N. Alalwan, L. Cheng, H. Al-Samarraie, R. Yousef, A. Ibrahim Alzahrani, and S. M. Sarsam, "Challenges and Prospects of Virtual Reality and Augmented Reality Utilization among Primary School Teachers: A Developing Country Perspective," Stud. Educ. Eval., vol. 66, no. March, p. 100876, 2020, doi: https://doi.org/10.1016/j.stueduc.2020.100876

[22] H. F. Hanafi et al., "Utilizing Animal Characters of a Mobile Augmented Reality (AR) Reading Kit to Improve Preschoolers' Reading Skills, Motivation, and Self-Learning: An Initial Study," pp. 94-107, doi: https://doi.org/10.3991/ijim.v15i24.26673

\section{Authors}

Ahmad Mursyidun Nidhom is a member of the International for the engineers and the computer scientist (IAENG), 174192, Hung To Road, Hongkong. He is active in conducting research on foreign collaborations and managing international journals. He also has a network of research collaborations in Southeast Asia. (E-mail: nidhom.ft@, um.ac.id).

Andika Bagus Nur Rahma Putra is a productive young lecturer at the Malang State University, Indonesia. He is active in writing scientific papers, researching, and developing learning technology. He also owns more than 100 educational copyrights and often conduct international collaborative research. (E-mail: andika.bagus.ft@um.ac.id).

Azhar Ahmad Smaragdina is a lecturer who is involved in international cooperation; he is also one of the innovators in the field of Education, more than 10 copyrights resulting from international research collaborations (E-mail: azhar.ft@um.ac.id).

Gres Dyah Kusuma Ningrum is a lecturer who is involved in the Development of national educator certification; She is a lecturer who has service collaborations throughout the nation and is a lecturer in developing learning innovations (E-mail: gres.dyah. ft@um.ac.id). 
Muhammad Afnan Habibi is a lecturer in the field of electronics who has various kinds of experience in international cooperation, besides that he is active in education quality assurance and research collaboration with European researchers (E-mail: afnan. habibi.ft@um.ac.id).

Jailani MD Yunos is an active professor at Tun Hussein Onn University Malaysia, Johor, Malaysia. He is one of the initiators of MyRivet Asia and collaborates with researchers in Southeast Asia (E-mail: jailani@uthm.edu.my).

Article submitted 2021-12-02. Resubmitted 2022-01-06. Final acceptance 2022-01-09. Final version published as submitted by the authors. 